\title{
Survivin is expressed in degenerated nucleus pulposus cells and is involved in proliferation and the prevention of apoptosis in vitro
}

\author{
YAZHOU LIN, BIN YUE, HONGFEI XIANG, YONG LIU, XUEXIAO MA and BOHUA CHEN \\ Department of Orthopedic Surgery, The Affiliated Hospital of Qingdao University, Qingdao, Shandong 266003, P.R. China
}

Received December 13, 2014; Accepted November 5, 2015

DOI: $10.3892 / \mathrm{mmr} .2015 .4605$

\begin{abstract}
Survivin is a unique inhibitor of apoptosis, which is frequently present within degenerated human nucleus pulposus (NP) cells. Survivin has been extensively investigated using proliferation and apoptosis assays in tumor cells; however, studies conducted on survivin in degenerative NP cells remain limited to date. The aim of the present study was to investigate survivin expression and its effects on the proliferation and apoptosis of degenerated NP cells in vitro. The expression levels of survivin in the NP cells of patients ( $>45$ years) with lumbar disc degenerative disease and the NP cells of patients ( $<25$ years) with lumbar vertebra fracture were assessed by reverse transcription-quantitative polymerase chain reaction. The effects on in vitro proliferation and apoptosis were investigated through transfection with a specific small interfering (si)RNA. The results of the present study demonstrated that survivin was expressed in the degenerated NP cells, but was undetectable in normal NP cells at the mRNA level. Survivin suppression following transfection with a specific survivin-siRNA reduced the proliferation rate of NP cells and enhanced sensitization to pro-apoptotic stimuli. Therefore, survivin was shown to be expressed and exhibit an important role in the proliferation and prevention of apoptosis of degenerated NP cells. Studies on survivin in NP cells may aid in increasing the understanding of the complex processes underlying NP cell degeneration, and could provide fundamental information for gene therapy to inhibit this degeneration in vitro.
\end{abstract}

\section{Introduction}

Approximately $80 \%$ of the aging population is suffering from lower back pain, an endemic problem that causes substantial disability (1-3). Intervertebral disc (IVD) degeneration is the

Correspondence to: Dr Bohua Chen, Department of Orthopedic Surgery, The Affiliated Hospital of Qingdao University, 16 Jiangsu Road, East District, Qingdao, Shandong 266003, P.R. China

E-mail: bhchen@hotmail.com

Key words: disc degeneration disease, nucleus pulposus, survivin, small interfering RNA, cell proliferation, apoptosis leading cause of lower back pain (4). However, conservative treatment (such as medication and physical therapy) and surgical treatments target symptom reduction, rather than repairing or decelerating the underlying degenerative process. Determining the mechanism underlying the degeneration of the IVD may aid in developing strategies to decelerate or reverse this process.

The IVD consists of two regions, namely, the inner nucleus pulposus (NP) and the outer annulus fibrosus (AF). Normal NP cells produce aggrecan and collagen type II. Aggrecans are polyanionic due to their high content of carboxyl and sulfate groups, and thus attract and bind water molecules, hydrating the tissue in order to resist compressive loads (5). Since NP cells have an important role in maintaining the integrity of IVD (6), NP cell loss resulting from necrosis and apoptosis contributes to disc degeneration (7-10). Therefore, the analysis of the apoptosis and proliferation of NP cells may provide a novel therapeutic approach for the reversal of the degenerative process.

Among the apoptosis signaling pathways, two predominant caspase-dependent signaling pathways may be observed: The intrinsic and the extrinsic signaling pathways, which are mediated by the mitochondria and death receptor, respectively. Numerous studies have demonstrated that the mechanism underlying apoptosis in degenerated NP cells involves the two types of signaling pathway, although the involvement varied among patients. The two signaling pathways ultimately induce caspase-3 to initiate apoptosis (11-14).

Survivin is a baculovirus inhibitor of apoptosis repeat motif protein, which is located on the long arm of chromosome 17 at position q25. It is abundantly expressed in embryonic tissues and in the majority of tumors, however, survivin is not present in normal differentiated cells (15-17). The predominant function of survivin is the regulation of mitosis progression and apoptosis inhibition (18). In embryonic tissues, survivin is expressed in a strictly regulated manner during development, and has an important role in the control of embryonic cell mitosis/cytokinesis and apoptosis (19). In human cancer, survivin expression detected by immunohistochemical staining is an important prognostic parameter. High survivin expression levels in tumors correlates with a more aggressive and invasive clinical phenotype, and poor prognosis and low responsiveness to chemotherapeutic agents can be expected $(20,21)$. Survivin has been proposed as a suitable molecular target for future anticancer therapies. However, 
a recent study reported a role of survivin in non-malignant tissues and normal cells (15). In rheumatoid arthritis and osteoarthritis, high mRNA and protein expression levels of survivin were observed, and results on the proliferation and apoptosis of chondrocytes were consistent with the findings of the present study (22-24).

The role of survivin in degenerated NP cells remains to be elucidated. The present study investigated the expression levels of survivin in human NP cells in vitro, and reported selective survivin expression in degenerated human NP cells. Further understanding of survivin expression and function in NP cells may be an important step towards understanding the mechanism underlying degeneration, and may prove useful in the development of future gene therapies to decelerate the degeneration of NPs.

\section{Materials and methods}

Materials. Degenerative human NP cells were donated by ten patients, which included six men and four women, with a mean age of 58 years (range, 47-66 years; Table I). All patients were diagnosed with disk degeneration using magnetic resonance imaging and had undergone spinal fusion to relieve their chronic lower back pain. The degenerative condition of intervertebral disk degeneration was evaluated according to the Pfirrmann's grading system (25). Normal NP cells were collected from two young male patients (aged 22 and 24 years) undergoing posterior nucleotomy in their left ventricles, spinal fusion, and decompression, and were stable within $24 \mathrm{~h}$ of trauma. The two men did not have any previous documented clinical history of lower back pain, and their cells were used as controls. The present study was approved by the Ethics Committee of the Affiliated Hospital of Qingdao University (Qingdao, China), and informed consent was signed by all patients involved in the present study, in which they agreed to provide their individual clinical information.

The tissue samples were harvested and collected under sterile conditions at The Affiliated Hospital of Qingdao University in 2014 between May and August. The patients with normal cells had been involved in trauma accidents. Complete culture medium [Dulbecco's modified Eagle's medium (DMEM)-F12, GE Healthcare Life Science GE Healthcare Life Science, Logan, UT, USA] supplemented with fetal calf serum (Gibco; Thermo Fisher Scientific, Inc., Waltham, MA, USA) maintained at $4^{\circ} \mathrm{C}$ was used as transport medium. All biopsies were delivered to the laboratory (the Medical Research Center at The Affiliated Hospital of Qingdao University) for processing of cell culture on the day of harvest.

Cell isolation and culture. Tissue samples were weighed and washed twice in phosphate-buffered saline (PBS). The NP and AF were separated based on their macroscopic morphologies by omitting the transitional zone, as previously described (6). Cells from each patient were isolated and cultured separately to avoid interference. The NP tissue samples were sectioned $\left(\sim 1 \mathrm{~mm}^{2}\right)$ prior to being digested with $0.25 \%$ trypsinase (GE Healthcare Life Science) at $37^{\circ} \mathrm{C}$ under gentle agitation. After 20 min, digestion was stopped using DMEM-F12 supplemented with $15 \%$ fetal calf serum, and the tissue samples were centrifuged at $560 \mathrm{x}$ g for $5 \mathrm{~min}$. Subsequently, $0.5 \%$ collagenase Type II (ICN Biomedicals Inc., Costa Mesa, CA, USA) was used to treat the cells at $37^{\circ} \mathrm{C}$ for $\sim 4 \mathrm{~h}$. The tissue samples were centrifuged at $560 \mathrm{x} \mathrm{g}$ for $5 \mathrm{~min}$ and washed three times with DMEM-F12 supplemented with $15 \%$ fetal calf serum.

The cells were transferred to a $12.5-\mathrm{cm}^{2}$ culture flask at a density of $10^{5}$ cells $/ \mathrm{ml}$. The cells were maintained in DMEM-F12 supplemented with $15 \%$ fetal calf serum and $1 \%$ penicillin/streptomycin (Invitrogen; Thermo Fisher Scientific, Inc.), and cultured in a $\mathrm{CO}_{2}$ incubator (SANYO Electric Co. Ltd., Moriguchi, Japan) at $37^{\circ} \mathrm{C}$ with humidity (95\%). The growth medium was changed every three days following cell adherence. All experiments were conducted during passage two, and sub-confluent cultures were used.

Cell culture in ischemic condition. NP cells were cultured in DMEM culture medium (glucose deprivation) in a $\mathrm{CO}_{2}$ incubator at $37^{\circ} \mathrm{C}$ with $1 \%$ oxygen and $95 \%$ humidity. These cells were subsequently used for analyzing caspase- 3 activity.

RNA extraction and reverse transcription-quantitative polymerase chain reaction $(R T-q P C R)$. mRNA survivin expression levels were assayed by RT-qPCR. Total mRNA was extracted from the NP cells using TRIzol (Invitrogen; Thermo Fisher Scientific, Inc.) according to a one-step method in the manufacturer's instructions. A total of $1 \mu \mathrm{g}$ mRNA was reverse transcribed into cDNA in $10 \mu 1$ reaction mixture using PrimeScript RT reagent (Takara Biotechnology Co., Ltd., Dalian, China), and the reaction product was treated with RNAse-free DNase I (Takara Biotechnology Co., Ltd.). The absorbance was measured at 260 and $280 \mathrm{~nm}$ using a Safire ${ }^{2}$ automatic microplate reader (Tecan Group Ltd., Männedorf, Switzerland ) for quantification and quality control.

PCR was conducted with the following cycling conditions in a LightCycler ${ }^{\circledR} 480$ II (Roche Diagnostics, Basel, Switzerland): $95^{\circ} \mathrm{C}$ for $5 \mathrm{~min}$ followed by 33 cycles of $94^{\circ} \mathrm{C}$ for $45 \mathrm{sec}, 56^{\circ} \mathrm{C}$ for $45 \mathrm{sec}, 72^{\circ} \mathrm{C}$ for $45 \mathrm{sec}$, and a final extension step at $72^{\circ} \mathrm{C}$ for $10 \mathrm{~min}$. The probes were designed using the PrimerExpress program (Applied Biosystems Life Technologies, Foster City, CA, USA). Total gene specificity was confirmed through BLAST searches (GenBank database sequences; www.ncbi. nlm.nih.gov/genbank/). The primers were purchased from Sangon Biotech Co. Ltd. (Shanghai, China; Table II). Human GAPDH was used as the internal control. In each experiment, the samples were analyzed in duplicates. The values for survivin were associated with those of their controls using the comparative $\mathrm{Cq}$ method ( $\Delta \Delta \mathrm{Cq}$ method).

Protein extraction and western blot analysis. For the cell culture extracts, adherent cells were washed with ice-cold PBS, and cell lysis was performed using $200 \mu \mathrm{l}$ radioimmunoprecipitation assay buffer (Aidlab Biotechnologies Co., Ltd, Beijing, China) with $2 \mu$ l phenylmethanesulfonyl fluoride (Shanghai Macklin Biochemical Co.,Ltd., Shanghai, China) on ice for $45 \mathrm{~min}$. The cells were removed by scraping. Subsequently, the lysis solution was centrifuged at $6,700 \mathrm{x} \mathrm{g}$ for $5 \mathrm{~min}$ at $4^{\circ} \mathrm{C}$. For western blot analysis of survivin, GAPDH was used as an internal control, and the proteins were separated by $10 \%$ SDS-PAGE (Beyotime Institute of Biotechnology, Haimen, China) prior to being 
Table I. Patient details and Pfirrmann grade.

\begin{tabular}{ccccc}
\hline Number & Gender & Age (years) & \multicolumn{1}{c}{ Diagnosis } & $\begin{array}{c}\text { Pfirrmann } \\
\text { grade }\end{array}$ \\
\hline 1 & Male & 47 & Disc degeneration (L4/15) & V \\
2 & Male & 54 & Disc degeneration (L5/S1) & IV \\
3 & Male & 61 & Disc degeneration (L4/15) & V \\
4 & Female & 59 & Disc degeneration (L4/15) & IV \\
5 & Female & 54 & Disc degeneration (L5/S1) & V \\
6 & Male & 66 & Disc degeneration (L4/15) & IV \\
7 & Female & 63 & Disc degeneration (L4/15) & V \\
8 & Male & 55 & Disc degeneration (L5/S1) & V \\
9 & Female & 63 & Disc degeneration (L5/S1) & V \\
10 & Male & 58 & Disc degeneration (L5/S1) & I \\
11 & Male & 22 & Lumber trauma (L4/15) & II \\
12 & Male & 24 & Lumber trauma (L4/15) & \\
\hline
\end{tabular}

Table II. Nucleotide sequences of sense and antisense primers.

\begin{tabular}{llc}
\hline Gene & \multicolumn{1}{c}{ Primer } & PCR product (bp) \\
\hline Survivin & F: CAGATGACGACCCCATAGAGGA & 141 \\
& R: CCTTTGCAATTTGTTCTTGGC & \\
GAPDH & F: GGATTTGGTCGTATTGGG & 205 \\
\hline
\end{tabular}

PCR, polymerase chain reaction; $F$, forward; $R$, reverse.

transferred onto immobilon-P membranes (EMD Millipore, Billerica, MA, USA). The membranes were blocked with 5\% fat-free dried milk and incubated with monoclonal rabbit antibody (cat. no. ab76424; Abcam, Cambridge, MA, USA) at $4^{\circ} \mathrm{C}$ for $8 \mathrm{~h}$. The membranes were washed three times with PBS (15 min per wash). The membranes were then incubated with horseradish peroxidase-conjugated secondary antibody, goat anti-rabbit IgG (dilution, 1:2,000; cat. no. CW0103; $\mathrm{CW}$ Bio, Beijing, China) at room temperature for $2 \mathrm{~h}$ and the bands were visualized using chemiluminescence (Pierce Biotechnology, Inc., Rockford, IL, USA). The images were analyzed using a Fusion FX7 (Vilber Lourmat, Marne-laVallée, France).

Survivin knockdown by small interfering (si)RNA. For transfection analysis, the cells were seeded into six-well plates at $4 \times 10^{5}$ cells/well for $4 \mathrm{~h}$ prior to knockdown being performed. For knockdown of survivin, an siRNA with the following sequence: Sense, 5'-GCGCCUGCACCCCGGAGCG-3' and antisense, 5'-CGCUCCGGGGUGCAGGCGC-3', was transfected as previously described $(24,26)$. An siRNA targeting green fluorescence protein (GFP) with the following sequence: Sense, 5'-GUGUGCUGUUUGGAGGUCTT-3', and antisense, 5'-GAACUCCAAACAGCACACCTT-3', was transfected to serve as the negative control. All siRNAs (Sangon Biotech Co., Ltd.) were used at a concentration of $100 \mathrm{nmol} / \mathrm{l}$, and transfected using X-treme GENE siRNA transfection reagent (Roche Diagnostics)

Caspase-3 activity assay. Apoptosis levels were investigated by measuring caspase-3 activity using a Caspase-3 Colorimetric Assay kit (BioVision Inc., Milpitas, CA, USA). The NP cells were counted and seeded at $1.5 \times 10^{6}$ cells for 24 or $48 \mathrm{~h}$ following survivin-specific or control siRNA transfection. The cells were then re-suspended in cell lysis buffer and $50 \mu \mathrm{l}$ of $2 \mathrm{X}$ reaction buffer (containing $10 \mathrm{mM}$ DTT; BioVision, Inc.) and $5 \mu \mathrm{l}$ DEVE-pNA were added. The samples were incubated for $90 \mathrm{~min}$ at $37^{\circ} \mathrm{C}$, and their absorbancies were read at $405 \mathrm{~nm}$ using a microplate reader (Sunrise; Tecan Group Ltd., Männedorf, Switzerland).

Measurement of cell proliferation by quantification of bromodeoxyuridine (BrdU) incorporation. A commercial ELISA cell proliferation assay (Roche Diagnostics) was used according to the manufacturer's protocol. A total of $48 \mathrm{~h}$ post-transfection with survivin-specific or control siRNA, the cells were seeded at a density of $7 \times 10^{3}$ and cultured in 96-well microtiter plates prior to being treated with $\mathrm{BrdU}$ (final concentration, $10 \mathrm{mM}$; Roche Diagnostics) for $6 \mathrm{~h}$. Following treatment with a fixation solution (Roche Diagnostics), the cells were labeled with anti-BrdU-POD Fab fragments (Roche Diagnostics). The bound antibody was then quantified using a peroxidase substrate 


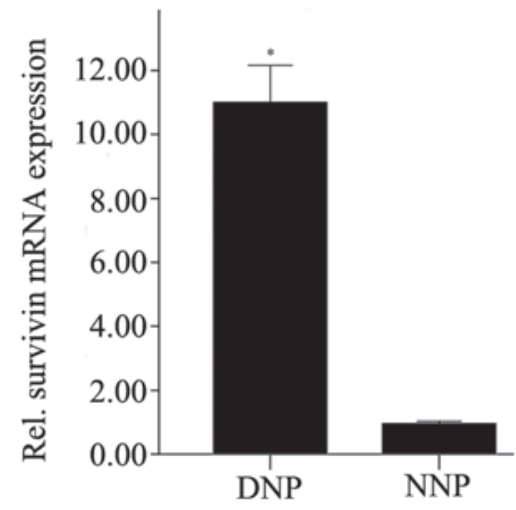

Figure 1. Survivin expression levels in DNP and NNP $\left(2^{-\Delta \Delta c q}\right)$. The data are presented as the mean \pm standard error of the mean. NP cells from the patients were analyzed for the mRNA expression levels of survivin by reverse transcription-quantitative polymerase chain reaction. Absent or low expression levels of survivin were detected in NNP, whereas survivin expression levels were high in DNP. The difference was statistically significant $\left({ }^{*} \mathrm{P}=0.01\right)$. DNP, degenerative human nucleus pulposus cells; NNP, normal nucleus pulposus cells.

A

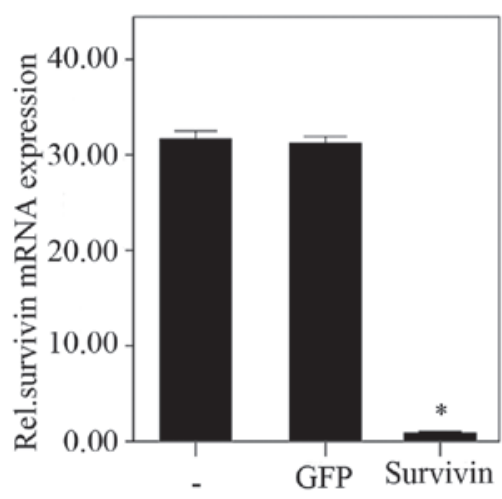

B

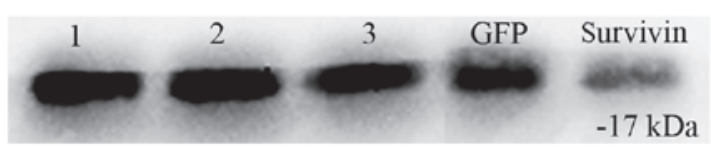

Figure 2. (A) Relative mRNA expression levels of survivin after transfection with siRNA as detected by reverse transcription-quantitative polymerase chain reaction $\left(2^{-\Delta \Delta c q}\right)$. The data are presented as the mean \pm standard error of the mean. Post-transfection ( $48 \mathrm{~h}$ ) with survivin-specific siRNA, the relative expression levels of survivin mRNA in nucleus pulposus cells were significantly reduced compared with GFP-siRNA transfected and non-transfected cells ( $\mathrm{P}<0.01)$. No significant difference was observed between GFP-siRNA transfected and non-transfected cells $(\mathrm{P}=0.57)$. (B) Western blot analysis of survivin protein expression levels in three degenerated nucleus pulposus cells (lanes 1, 2 and 3). Protein expression levels $48 \mathrm{~h}$ post transfection with GFP and survivin-specific siRNA are shown. Survivin protein expression levels in the three independent primary nucleus pulposus cells and nucleus pulposus cells transfected with GFP siRNA were stable, and no significant difference was observed. Post transfection with survivin-siRNA, survivin protein expression levels were significantly reduced. GFP, green fluorescent protein; siRNA, small interfering RNA.

(luminol/4-iodophenol; Roche Diagnostics), and light emission was measured using a luminometer (Sunrise; Tecan Group Ltd.).

Statistical analysis. All values are presented as the mean \pm standard error of the mean. Student's t-test and one-way

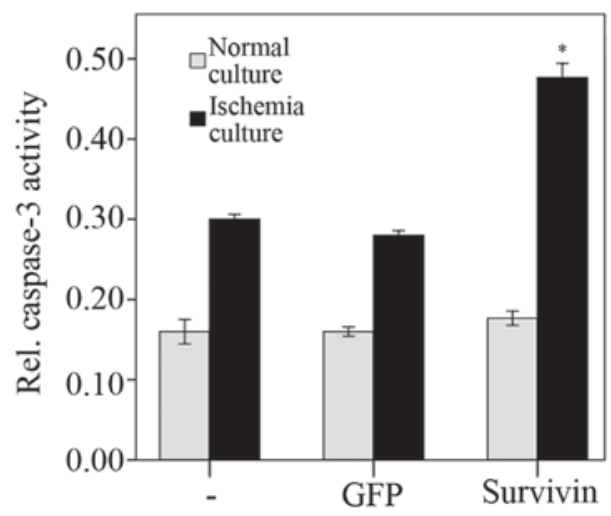

Figure 3. Caspase-3 activity levels 48 h post transfection under regular culture conditions and under ischemic culture conditions. The data are presented as the mean \pm standard error of the mean. Under normal culture conditions (unstressed), no significant difference was observed between the cells transfected with survivin-specific siRNA and control siRNA $(\mathrm{P}=0.49)$. Under ischemic culture conditions (1\% oxygen and glucose deprivation), caspase-3 activity significantly increased ( $\mathrm{P}<0.001)$. In each group, the difference was statistically significant between the different culture conditions $(\mathrm{P}<0.01)$. GFP, green fluorescent protein; siRNA, small interfering RNA.

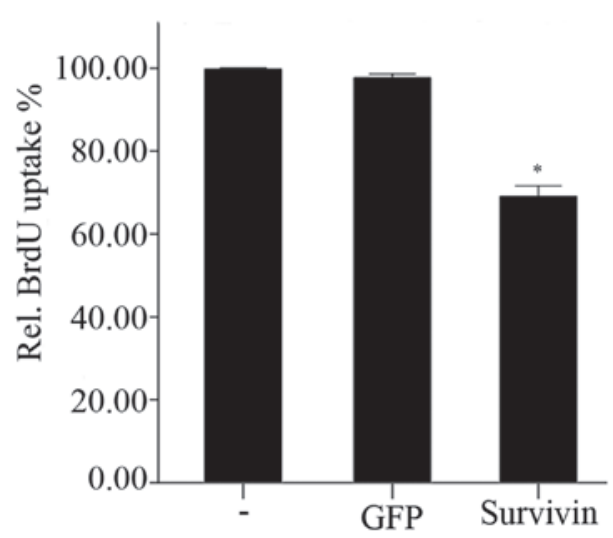

Figure 4. Relative BrdU uptake was used to measure cell proliferation $48 \mathrm{~h}$ post-transfection. Data are presented as the mean \pm standard error of the mean. BrdU uptake by nucleus pulposus cells post transfection with survivin-siRNA was significantly reduced compared with the control groups $\left({ }^{*} \mathrm{P}<0.01\right)$, whereas no significant difference was observed between the control groups $(\mathrm{P}=0.35)$. BrdU, bromodeoxyuridine; siRNA, small interfering RNA.

analysis of variance (ANOVA) and a post hoc Fisher's Least Significant Difference (LSD) test were used to analyze the statistical significance of the differences. Statistical analyses were performed using SPSS 19 (IBM, Armonk, NY, USA). $\mathrm{P}<0.05$ was considered to indicate a statistically significant difference.

\section{Results}

Survivin is expressed in degenerated NP cells. Survivin expression in NP cells was analyzed by RT-qPCR. The mRNA expression levels of survivin in degenerative NP cells were significantly higher compared with that in normal NP cells $(\mathrm{P}=0.01$; Fig. 1).

Expression levels of survivin post-transfection with survivin-specific siRNA. Survivin expression levels in 
degenerative NP cells were analyzed using RT-qPCR and western blot analysis following transfection with survivinspecific siRNA. Protein and mRNA survivin expression levels were significantly reduced $48 \mathrm{~h}$ post-transfection with survivin-specific siRNA, compared with the negative and blank control groups $(\mathrm{P}<0.01)$. No significant difference was observed between the negative and blank control groups $(\mathrm{P}=0.57$; Fig. 2A and $\mathrm{B})$.

Survivin knockdown leads to an increased sensitivity to pro-apoptotic stimuli. The activity levels of caspase-3 $48 \mathrm{~h}$ post-transfection with siRNA were assayed. Under normal culture conditions (unstressed), transfection with survivin-specific siRNA did not lead to significantly altered caspase-3 activity levels, compared with the negative and blank control groups ( $\mathrm{P}=0.49$; Fig. 3$)$. However, when exposed to ischemia in vitro (1\% oxygen and glucose deprivation), caspase-3 activity levels significantly increased $48 \mathrm{~h}$ after transfection with siRNA (survivin siRNA + in vitro ischemia compared with GFP siRNA + in vitro ischemia and untransfected + in vitro ischemia, $\mathrm{P}<0.001$; Fig. 3). ANOVA and subsequent LSD tests revealed increased apoptotic rates under all transfection conditions (untransfected + unstressed compared with untransfected + in vitro ischemia, $\mathrm{P}<0.01$; GFP siRNA + unstressed compared with GFP siRNA + in vitro ischemia, $\mathrm{P}<0.01$; and survivin siRNA + unstressed compared with survivin siRNA + in vitro ischemia, $\mathrm{P}<0.01$ ) where unstressed refers to the NP cells that were cultured in normal rather than ischemic conditions. The transfection of GFP had no significant effect on apoptotic levels (untransfected + unstressed compared with GFP siRNA + unstressed, $\mathrm{P}=0.64$; and untransfected + in vitro ischemia compared with GFP siRNA + in vitro ischemia, $\mathrm{P}=0.17$ ).

Survivin knockdown leads to reduced proliferation rates. The effects of transfection with survivin-specific siRNA on the proliferation of NP cells is shown in Fig. 4. BrdU uptake was significantly $(\mathrm{P}<0.01)$ reduced $48 \mathrm{~h}$ following knockdown of survivin, compared with the negative and blank control groups. However, transfection with GFP-siRNA did not lead to any significant alterations in BrdU uptake after $48 \mathrm{~h}$, compared with the blank control group $(\mathrm{P}=0.347)$.

\section{Discussion}

Degenerative disc disease is a serious and common health care problem, and therapeutic strategies have traditionally focused primarily on treating the symptoms. Therefore, novel methods that would stimulate the regeneration of disc tissues or decelerate the progress of age-associated disc degeneration are required. Thus, it is important to understand the changes that occur with aging, the causes of these changes, and the mechanism underlying degeneration.

Several studies have investigated the mechanisms underlying disc degeneration, including a decrease in cellular concentration, cell senescence, cell apoptosis, decreasing extracellular matrix anabolism and increasing extracellular matrix catabolism $(27,28)$. The role of oncofetal gene survivin has been extensively investigated in cell proliferation and apoptosis in tumor cells $(29,30)$. However, limited data is available regarding its expression in degenerative NP cells. Yang et al (31) reported that survivin was expressed in fetal disc tissue samples and was differentially expressed between degenerated NP tissue samples and normal NP tissue samples $(31,32)$. Immunohistochemical staining demonstrated that survivin expression was present in 20-, 26- and 28-week fetal age intervertebral discs, and the differences in expression levels between samples were not statistically significant. Survivin expression levels were detectable in degenerated NP tissue samples, whereas they were significantly downregulated in normal NP tissue $(\mathrm{P}=0.048)$. These results demonstrated that survivin has an important role in fetal intervertebral disc growth, and is likely to be involved in the regulation of apoptosis and cell proliferation during the degeneration of NP tissue $(31,32)$.

Based on the above-mentioned results $(31,32)$, the difference between the expression levels of survivin in degenerative NP cells and normal NP cells was investigated in the present study. The mRNA expression levels of survivin were significantly increased in degenerative NP cells, whereas absent or low expression levels were reported in normal NP cells, which was concordant with the survivin expression levels reported in the corresponding tissue samples of a previous study (32). The results indicated the expression of survivin gene transcription and translation in degenerative NP cells, and suggested that survivin may have a role in the degeneration of NP cells. Therefore, based on the effects and function of survivin, alterations in cell proliferation and apoptosis were measured following survivin knockdown by siRNA. The results revealed the role of survivin in the degeneration of NP cells.

siRNA is an effective tool for silencing the expression of survivin, and GFP-siRNA was used as a negative control in the present study. At the RNA level, survivin knockdown $48 \mathrm{~h}$ after transfection led to a marked reduction in survivin mRNA expression levels. The protein expression level of survivin was also significantly decreased $48 \mathrm{~h}$ post transfection.

Cell proliferation was measured through the quantification of BrdU incorporation. BrdU uptake in the degenerative NP cells was reduced following survivin knockdown and suppression. These results suggested a role for survivin in cell proliferation. Numerous studies have demonstrated that survivin is essential for mitosis and cell division, and knockdown of survivin function has been associated with cell division defects, demonstrated by the presence of supernumerary centrosomes, the formation of multipolar mitotic spindles and the failure of cytokinesis (33-35). Therefore, in degenerative NP cells, the re-expression of survivin may be useful to increase cell proliferation in order to compensate for the decreasing cellular concentration during the degenerative process.

Survivin also has an anti-apoptotic function. No alteration between the activity levels of caspase- 3 in the positive and control groups were demonstrated in the unstressed NP cells. These results may be attributable to the culture conditions (sufficient oxygen and glucose). However, the spinal disc is the largest avascular organ in the body and does not directly supply blood to NP cells $(36,37)$, therefore material and gas exchange predominantly depends on diffusion from the nearest blood supply. Owing to the progressive age-associated degeneration and calcification of the cartilage endplate (27), the number of 
arteries that supply the periphery of the disc decreases. This decrease impairs the diffusion function of the disc such that nutrition and oxygen supply deteriorate. Therefore, degenerative NP cells are under relatively ischemic conditions. Following in vitro ischemic culture (1\% oxygen, glucose deprivation), caspase-3 activity levels in the NP cells were significantly increased compared with unstressed NP cells, and after transfection of survivin-siRNA, caspase-3 activity levels significantly increased. The results demonstrated that ischemic culture conditions induced NP cell apoptosis, and expression of survivin may contribute to the reduction of caspase-3 activity exhibiting an anti-apoptotic function in the degeneration process.

In the present study, siRNA was used to investigate the role of survivin in degenerative NP cells, and the results revealed the effects of survivin-siRNA transfection on the proliferation and apoptosis of NP cells under ischemic conditions in vitro. The signaling pathway of survivin in cell division and apoptosis requires further investigation in order to provide a greater understanding of the mechanism underlying survivin regulation. In addition, the construction of lentiviral-survivin for transfection of the degenerative NP cells, and examination of the effects of long-term expression of survivin in degenerative NP cells will be a further research direction.

In conclusion, to the best of our knowledge, the present study demonstrated for the first time that survivin is expressed in degenerative NP cells, and analyzed the general functions of survivin, including in cell proliferation and apoptosis. The results of the present study demonstrated that the expression of survivin had an important role in degenerative NP cells. The data suggested that survivin was a potential target for gene therapy, and supplied fundamental information regarding decreasing NP cell apoptosis by increasing survivin expression levels in order to decelerate the degeneration of NP cells.

\section{Acknowledgements}

The present study was supported by a grant from the National Natural Science Foundation of China (grant no. 81171758).

\section{References}

1. Hoy D, Brooks P, Blyth F and Buchbinder R: The Epidemiology of low back pain. Best Pract Res Clin Rheumatol 24: 769-781 2010.

2. Takahashi K, Aoki Y and Ohtori S: Resolving discogenic pain. Eur Spine J 17 (Suppl 4): S428-S431, 2008.

3. Hillman M, Wright A, Rajaratnam G, Tennant A and Chamberlain MA: Prevalence of low back pain in the community: Implications for service provision in Bradford, UK. J Epidemiol Community Health 50: 347-352, 1996.

4. Chen WH, Liu HY, Lo WC, Wu SC, Chi CH, Chang HY, Hsiao SH, Wu CH, Chiu WT, Chen BJ and Deng WP: Intervertebral disc regeneration in an ex vivo culture system using mesenchymal stem cells and platelet-rich plasma. Biomaterials 30: 5523-5533, 2009.

5. Pockert AJ, Richardson SM, Le Maitre CL, Lyon M, Deakin JA, Buttle DJ, Freemont AJ and Hoyland JA: Modified expression of the ADAMTS enzymes and tissue inhibitor of metalloproteinases 3 during human intervertebral disc degeneration. Arthritis Rheum 60: 482-491, 2009.

6. Ding F, Shao ZW, Yang SH, Wu Q, Gao F and Xiong LM: Role of mitochondrial pathway in compression-induced apoptosis of nucleus pulposus cells. Apoptosis 17: 579-590, 2012

7. Vonk LA, Kroeze RJ, Doulabi BZ, Hoogendoorn RJ, Huang C, Helder MN, Everts V and Bank RA: Caprine articular, meniscus and intervertebral disc cartilage: An integral analysis of collagen network and chondrocytes. Matrix Biol 29: 209-218, 2010.
8. Zhao CQ, Jiang LS and Dai LY: Programmed cell death in intervertebral disc degeneration. Apoptosis 11: 2079-2088, 2006.

9. Zhao CQ, Liu D, Li H, Jiang LS and Dai LY: Interleukin-1beta enhances the effect of serum deprivation on rat annular cell apoptosis. Apoptosis 12: 2155-2161, 2007.

10. Gruber HE and Hanley EN Jr: Analysis of aging and degeneration of the human intervertebral disc. Comparison of surgical specimens with normal controls. Spine (Phila Pa 1976) 23: 751-757, 1998.

11. Ha KY, Kim BG, Kim KW, Oh IS and Seo JY: Apoptosis in the sequestrated nucleus pulposus compared to the remaining nucleus pulposus in the same patient. Spine (Phila Pa 1976) 36: 683-689, 2011.

12. Kaneyama S, Nishida K, Takada T, Suzuki T, Shimomura T, Maeno K, Kurosaka M and Doita M: Fas ligand expression on human nucleus pulposus cells decreases with disc degeneration processes. J Orthop Sci 13: 130-135, 2008.

13. Kuo YJ, Wu LC, Sun JS, Chen MH, Sun MG and Tsuang YH: Mechanical stress-induced apoptosis of nucleus pulposus cells: An in vitro and in vivo rat model. J Orthop Sci 19: 313-322, 2014.

14. Park JB, Lee JK, Park EY and Riew KD: Fas/FasL interaction of nucleus pulposus and cancer cells with the activation of caspases. Int Orthop 32: 835-840, 2008.

15. Li F and Brattain MG: Role of the Survivin gene in pathophysiology. Am J Pathol 169: 1-11, 2006.

16. Wheatley SP and McNeish IA: Survivin: A protein with dual roles in mitosis and apoptosis. Int Rev Cytol 247: 35-88, 2005.

17. Ambrosini G, Adida C and Altieri DC: A novel anti-apoptosis gene, survivin, expressed in cancer and lymphoma. Nat Med 3: 917-921, 1997.

18. Li F and Ling X: Survivin study: An update of "what is the next wave'? J Cell Physiol 208: 476-486, 2006.

19. Jiang Y, de Bruin A, Caldas H, Fangusaro J, Hayes J, Conway EM, Robinson ML and Altura RA: Essential role for survivin in early brain development. J Neurosci 25: 6962-6970, 2005.

20. Zhao J, Tenev T, Martins LM, Downward J and Lemoine NR: The ubiquitin-proteasome pathway regulates survivin degradation in a cell cycle-dependent manner. J Cell Sci 113 Pt 23: 4363-4371, 2000.

21. Tanaka K, Iwamoto S, Gon G, Nohara T, Iwamoto M and Tanigawa N: Expression of survivin and its relationship to loss of apoptosis in breast carcinomas. Clin Cancer Res 6: 127-134, 2000.

22. Lechler P, Balakrishnan S, Schaumburger J, Grässel S, Baier C, Grifka J, Straub RH and Renkawitz T: The oncofetal gene survivin is re-expressed in osteoarthritis and is required for chondrocyte proliferation in vitro. BMC Musculoskelet Disord 12: 150, 2011.

23. Baran M, Möllers LN, Andersson S, Jonsson IM, Ekwall AK, Bjersing J, Tarkowski A and Bokarewa M: Survivin is an essential mediator of arthritis interacting with urokinase signalling. J Cell Mol Med 13: 3797-3808, 2009.

24. Bokarewa M, Tarkowski A and Magnusson M: Pathological survivin expression links viral infections with pathogenesis of erosive rheumatoid arthritis. Scand J Immunol 66: 192-198, 2007.

25. Pfirrmann CW, Metzdorf A, Zanetti M, Hodler J and Boos N: Magnetic resonance classification of lumbar intervertebral disc degeneration. Spine (Phila Pa 1976) 26: 1873-1878, 2001.

26. Warnecke C, Zaborowska Z, Kurreck J, Erdmann VA, Frei U, Wiesener M and Eckardt KU: Differentiating the functional role of hypoxia-inducible factor (HIF)-1alpha and HIF-2alpha (EPAS-1) by the use of RNA interference: Erythropoietin is a HIF-2alpha target gene in Hep3B and Kelly cells. FASEB J 18: 1462-1464, 2004.

27. Buckwalter JA: Aging and degeneration of the human intervertebral disc. Spine (Phila Pa 1976) 20: 1307-1314, 1995.

28. Buckwalter JA, Woo SL, Goldberg VM, Hadley EC, Booth F, Oegema TR and Eyre DR: Soft-tissue aging and musculoskeletal function. J Bone Joint Surg Am 75: 1533-1548, 1993.

29. Ghadimi MP, Young ED, Belousov R, Zhang Y, Lopez G, Lusby K, Kivlin C, Demicco EG, Creighton CJ, Lazar AJ, et al: Survivin is a viable target for the treatment of malignant peripheral nerve sheath tumors. Clin Cancer Res 18: 2545-2557, 2012.

30. Romagnoli M, Séveno C, Bataille R and Barillé-Nion S: Survivin in cancerology: Molecular aspects and therapeutic applications. Med Sci (Paris) 24: 821-827, 2008 (In French).

31. Yang KS, Yue B and Ma XX: The expression of survivin and its significance in fetal intervertebral disc. Qingdao Daxue Yixueyuan Xuebao 49: 205-206, 2013.

32. Yang KS: The expression of survivin and its significance inintervertebral disc. Dissertation. Qingdao University, 2013. 
33. Chen J, Wu W, Tahir SK, Kroeger PE, Rosenberg SH, Cowsert LM, Bennett F, Krajewski S, Krajewska M, Welsh K, et al: Down-regulation of survivin by antisense oligonucleotides increases apoptosis, inhibits cytokinesis and anchorage-independent growth. Neoplasia 2: 235-241, 2000.

34. Reed JC and Bischoff JR: BIRinging chromosomes through cell division-and survivin' the experience. Cell 102: 545-548, 2000.

35. Skoufias DA, Mollinari C, Lacroix FB and Margolis RL: Human survivin is a kinetochore-associated passenger protein. J Cell Biol 151: 1575-1582, 2000.
36. Anderson DG and Tannoury C: Molecular pathogenic factors in symptomatic disc degeneration. Spine J 5 (6 Suppl): S260-S266, 2005.

37. Kim KW, Lim TH, Kim JG, Jeong ST, Masuda K and An HS: The origin of chondrocytes in the nucleus pulposus and histologic findings associated with the transition of a notochordal nucleus pulposus to a fibrocartilaginous nucleus pulposus in intact rabbit intervertebral discs. Spine (Phila Pa 1976) 28: 982-990, 2003. 